\title{
The Application of 4D Seismic in Niger Delta Basin: A Review
}

\author{
Ayorinde Janet Olaide $^{1^{*}} \quad$ Ehinola Olugbenga ${ }^{2} \quad$ Durogbitan Abimbola ${ }^{3}$ \\ 1.Department of Geology and Mineral Science, University of Ilorin \\ 2.Department of Geology, University of Ibadan \\ 3.Amni International Petroleum Dev Coy
}

\begin{abstract}
Time-lapse seismic also known as 4D seismic is one of the advanced techniques employed in the oil and gas industry for petroleum production management and monitoring for over 20years. It involves carrying out two or more 3D seismic at different calendar times, before and after production over the same reservoir. We present advances in Time Lapse 3D seismic (also known as 4D seismic) and its application in the Niger Delta basin of Nigeria. Over the years, the technique has been used in Niger Delta to understand reservoir drainage performance, enable better well placement, identifying bypassed oil, detecting fluid communication, understanding of internal architecture of the reservoirs, and locating infill wells for future re-development. 4D seismic has demonstrated its potential and it is fast becoming a standard tool in the oil companies.
\end{abstract}

DOI: $10.7176 /$ APTA/83-05

Publication date: February $29^{\text {th }} 2020$

\section{INTRODUCTION}

Time-lapse seismic also known as 4D Seismic is the study of changes in seismic attributes over a period. Fourdimensional seismic reservoir monitoring is the study of changes in seismic amplitude through the acquisition of various vintages of seismic data over the same location in a producing reservoir or field. 4D reservoir monitoring helps us to understand the changes in the properties of an oil-producing reservoir in both 3D space and time. This knowledge is extremely vital and ever more pressing in the management of a producing reservoir. Globally, the already consumed oil is almost the same in terms of volume, with the remaining discovered unproduced oil reserves. There is a vast amount of oil, which is rapidly consumed, while additional conventional reserves are becoming challenging to explore.

It is essential for the industry as well as consumers that we produce this remaining oil as reliably and proficiently as possible. We will not be able to produce the remaining oil reliably and optimally if we have no idea what is happening in the reservoir. Optimization includes aspects of safety, environmental impact, recovery factor, and timeliness and, of course, cost and profit. Time-lapse seismic data can be a significant contributor to the knowledge of what is happening and where it is happening in our reservoirs. We need to work as quickly as possible with those who can use this knowledge, so we all can benefit from 4D surveys.

The main goal of oil production is to maximize productivity and hence profitability, achieving this goal will include minimizing the cost of production as well as enhancing field recovery through optimization. A key to successful field operations is reservoir surveillance. As we will see, 4D seismic technology is a crucial surveillance tool that used to enhance oil recovery, to optimize field development planning, help increase reserves and recovery, and ultimately maximize efficiency.

Time-lapse seismic data have the potential to image the movement of fluid movement and changes in pressure and temperature in the reservoir volume between the wells to improve reservoir management and infill drilling. The main applications of 4D seismic includes but not limited to locating bypassed oil: monitoring injected fluids such as water, steam, and CO2; identifying pressure compartments; and mapping flow paths and barriers

Currently, new insight and knowledge emerges in 4D application as improvement in 4D seismic technology continues to evolve. Its use has expanded from locations in the North Sea to others in the Gulf of Mexico, West Africa, Brazil, Asia, Australia, and onshore North America. Its Geologic settings have also moved from Tertiary clastic reservoirs, which are highly responsive to fluid and pressure changes, to older clastics and then to carbonates. Applicability has expanded to include compacting reservoirs, enhanced oil recovery, and environmental monitoring.

\section{THE HINT BEHIND 4D SEISMIC}

The concept of time-lapse seismic is misleadingly simple if it is seen as simply the difference between two 3D seismic surveys or two 2D surveys. We use repeated 3D seismic data, shot over a producing field, to help us monitor and predict the inter-well changes in reservoir properties that result from the field's depletion. The fourth dimension is the calendar time (T). Under satisfactory circumstances, seismic data can help to notice reservoir properties changes, such as fluid saturation and pressure, resulting in elastic properties changes. 4D seismic helps to detect and monitor changes in temperature in thermal recovery processes, and in compacting reservoirs, it also detects porosity and stress changes. Time-lapse seismic is a field-scale reservoir surveillance tool that is used in 
producing field.

4D seismic interpretation involves subtracting the differences of seismic images; the difference reduces the effect of lithologic variations on elastic properties and increases the effect of production.

The basic concept is illustrated in Figure 1, A seismic survey is usually acquired before production, or before we start a secondary or enhanced-recovery process, this serves as the primary or baseline conditions of the reservoir. Sometime in the future, at a time-dependent on the recovery process, or at an estimated time after production, we duplicate the survey. The difference between the second (or monitor) survey and the baseline survey is 4D seismic and this can then be interpreted with the reservoir changes because of production. Where 4D seismic is applied properly, the technique increases reserves and recovery by:-

- locating undrained reserves and pinpointing bypassed oil reserves.

- improving the development of infill-well locations and flood patterns

- improving reservoir characterization methods, recognizing compartmentalization, and mapping permeability pathways.

Likewise, 4D seismic can assist us to optimize the field-development plan by:-

- Minimizing the number of dry holes and hence reducing operating costs

- Reducing the uncertainty of reservoir-model, resulting in more effective and reliable reservoir management.

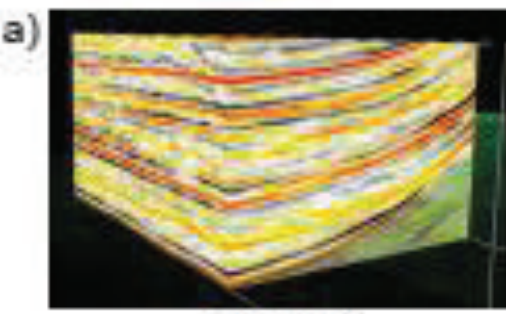

Baseline

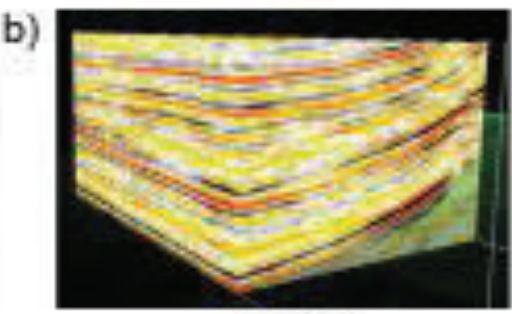

Monitor

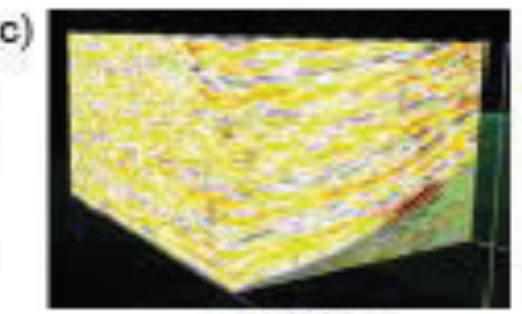

Difference

Figure 1. At its basic level, 4D seismic is a simple concept. A seismic survey acquired before production (a) establishes the initial or baseline conditions of the reservoir. Sometime after production begins. (b) a monitor survey is acquired (c) The difference between the two surveys is interpreted in terms of reservoir changes resulting from production

\section{NORMALIZED ROOT MEAN SQUARE (NRMS)}

The success and reliability of 4D seismic monitoring is dependent on the measurement of subtle changes in the earth's response because of gas and oil production. Therefore, the detectability and success of 4D seismic hinges on the ability to produce responses that are repeatable against those subtle changes that are measured. 4D repeatability depends mostly on repeating the acquisition parameters such as the receiver and source positions, wavelet and noise conditions, and subsequent processing.

What repeatability means in time-lapse seismic is not that everything should be the same in both the base and monitor survey. The ultimate significant purpose of time-lapse seismic is to emphasize the seismic response changes due to production or injection changes. Non-repeatable noise is every other thing that affects seismic responses. Mohsen Dadashpour 2009.

Repeatability is estimated over a time gap of the data and away from producing zones. Those measures can include calculations of spectral consistency, the correlation coefficient, time-shift errors, the amplitude ratio, and root-mean-square (RMS) amplitude of the differences. The most commonly quoted measures of repeatability in the literature, however, are the normalized RMS difference (hereafter referred to as simply NRMS) and (to a lesser extent) the predictability (PRED), both of which are discussed by Kragh and Christie (2002).

The NRMS value is simply the RMS amplitude of the difference, normalized by the average of the RMS amplitudes of the baseline and monitor:

$$
\mathrm{NRMS}=\frac{2 \mathrm{rms}(\text { monitor }- \text { base })}{\operatorname{rms}(\text { monitor })+\operatorname{rms}(\text { base })}
$$

Every basin and each field are unique in their way; hence, what applies to one field may not apply to another field. The amount of money and time required for an interpretable and successful 4D seismic data survey depends on different factors such as water depth and the characteristics of the overburden heterogeneity. The 4D signal also depends on the required level of the acquisition effort, for example, a small 4D response or heterogeneities such as channels near the seabed might require, as much effort on its acquisition, effort that would have been used for 
a shallow water North Sea Survey will likely be used. The NRMS-value is used to characterize the repeatability of two-time lapse surveys. Typical NRMS-values for some of the early 4D studies, for example, the Gullfaks 4D study (Landrø et al., 1999, Landrø, 1999b) are 60-80\%. Current 4D studies using steerable streamer technology (Goto et al., 2004) typical NRMS-values might be between 10 to 30\%. For land data, the NRMS-values are often higher, because of acquisition problems and seasonal changes within the near-surface layers.

Measures of 4D image repeatability, such as the NRMS value, are useful tools in estimating the quality and reliability of 4D seismic data. Nevertheless, each measure has limitations. Hence, we should use several measures of repeatability to characterize nonrepeatable noise and interpretation uncertainties.

- Similarity in survey geometry, often described by $\Delta S+\Delta R$, can be related to image repeatability, at least in the North Sea. Nevertheless, lessons learned in the North Sea might or might not be applicable in other areas of the world. For instance, in deepwater fields, NRMS and other repeatability measures can be less sensitive to surveygeometry differences

- Fields with greater overburden complexity normally have poorer repeatability images and higher NRMS values than those with a less complex overburden. Efforts to improve geometry repeatability in acquisition have the most impact on image repeatability for fields with complex overburdens.

- 4D Image repeatability is also dependent on other factors, such as residual nonrepeatable multiples and ambient noise. There are 4D surveys where repeatability dominate geometry and there are surveys in which other factors are more important. Johnston (2013)

In many fields, non-repeatability can be reduced to levels at which even slight 4D signals can be detectable, Though, application of those strategies comes at a cost. Hence, the effort put into 4D seismic acquisition must be equal to the likely level of 4D detectability and by factors such as sea-bottom conditions, reservoir depth, water depth, and operational constraints. Finally, image repeatability not only implies similar acquisition geometry but then again reliable and repeatable processing.

\section{THE ROCK PHYSICS BEHIND 4D SEISMIC}

During production, changes in seismic response are a result of changes in velocity and density caused by changes in the reservoir's fluid saturation, pressure, porosity, and temperature. The field of Seismic rock physics is the connection between the static and dynamic reservoir properties and the elastic properties of the reservoir rock. The study and understanding of the seismic rock physics of a reservoir (sometimes known at the Petro elastic model, or PEM) is important for understanding the changes in the seismic response that result from production. Therefore, the rock-physics model is part of any qualitative or quantitative 4D seismic interpretation. In addition, it is a fundamental input to 4D modeling and feasibility analyses, the rock physics behind 4D seismic is no different from the rock physics behind hydrocarbon-indicator analysis or Amplitude Versus Offset /AVA. Nevertheless, let us understand one thing, a strong preproduction seismic response does not necessarily mean a strong 4D response. Likewise, a weak preproduction seismic response does not necessarily mean there will be no 4D signal. In 4Dseismic rock physics, what we are concerned about is the changes in the elastic properties and not their absolute values. Several factors influence the seismic properties of reservoir rocks. Such factors and their effects are shown in Table 1.

Table 1. Factors that influence seismic properties of sedimentary rocks, with increasing importance from top to bottom. After Wang (2001).

\begin{tabular}{lll}
\hline \multicolumn{1}{c}{ Rock properties } & \multicolumn{1}{c}{ Fluid properties } & \multicolumn{1}{c}{ Environment } \\
\hline Compaction & Viscosity & Frequency \\
Consolidation history & Density & Stress history \\
Age & Wettability & Depositional environment \\
Cementation & Fluid composition & Temperature \\
Texture & Phase & Reservoir process \\
Bulk density & Fluid type & Production history \\
Clay content & Gas/oil, gas/water values & Layer geometry \\
Anisotropy & Saturation & Net reservoir pressure \\
Fractures & - & - \\
Porosity & - & - \\
Lithology & - & - \\
Pore shape & - & - \\
\hline
\end{tabular}


a)

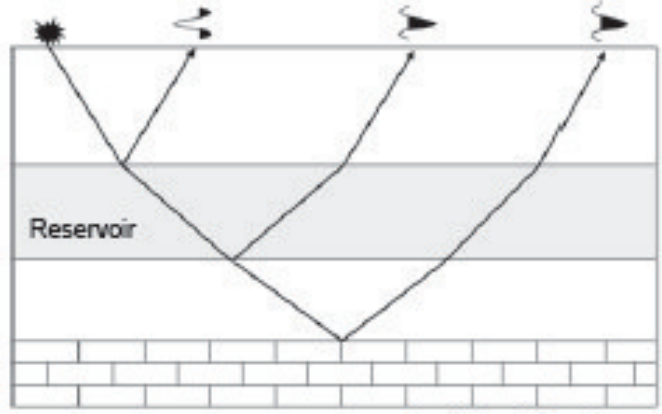

b)

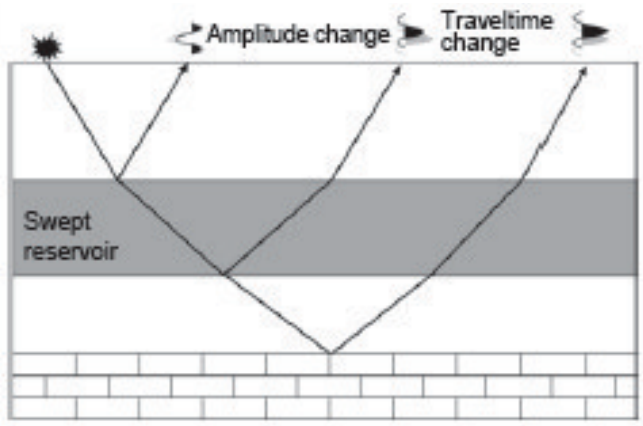

Figure 2. 4D seismic at its simplest. (a) Baseline seismic survey in which we record reflection amplitude and arrival time. (b) Monitor survey after reservoir sweep. In 4D seismic, we evaluate changes in amplitude and arrival time. Of course, it is never that simple. After Johnston 2013.

Let us assume that the reservoir in Figure 2a contains oil that will be produced by an active aquifer. Water will eventually replace most of the oil (to the value of Srow) in the reservoir, as shown in Figure $2 \mathrm{~b}$. The replacement of oil with water will result in an increase in velocity and density and hence in impedance of the reservoir. Repeating the seismic survey after the waterflood. Since the reservoir's impedance has changed, the amplitudes of reflections at the top and bottom of the reservoir are different from those recorded in Figure 2a (the baseline survey).

Changes in fluid saturation can have a great effect on P-wave velocity and impedance. In 4D seismic, one thing we will like to forecast is how impedance changes are going to be. Generally, as illustrated in Figure 3 the elastic moduli of a reservoir rock saturated with one fluid, we will want to forecast what that rock's moduli will be when the rock is saturated with a different fluid.

Gassmann's (1951) equation helps to solve the fluid-substitution problem. Gassmann derived a general relationship between the "dry" rock, or skeletal frame moduli, and the saturated rock moduli. Among the many forms of Gassmann's equation are:

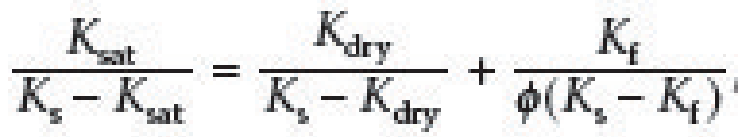

Fluid A

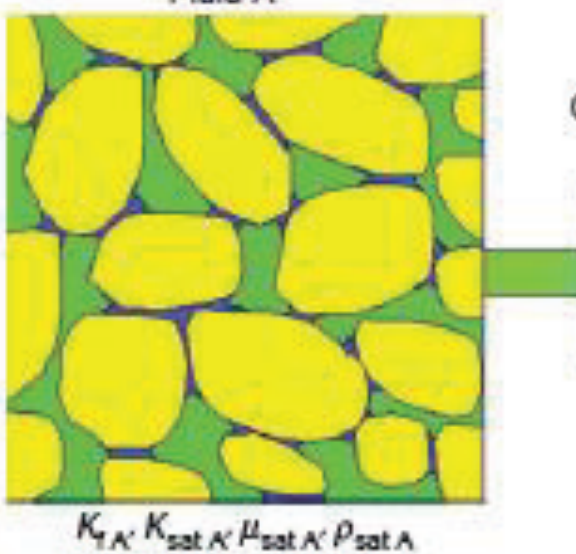

Fluid B

Common rock properties

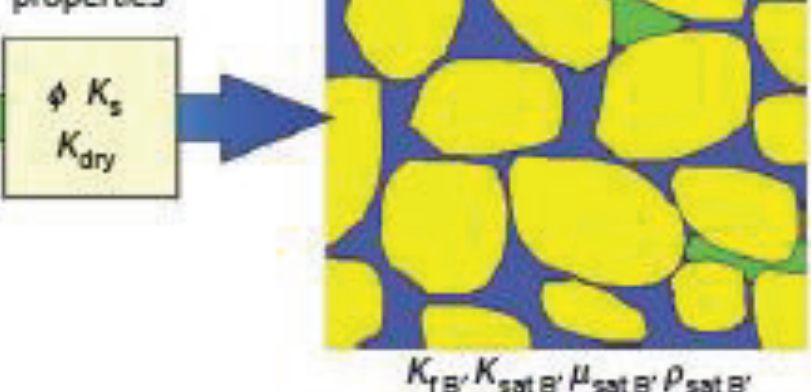

Figure 3. The general problem of fluid substitution. Given the elastic properties of a reservoir saturated with fluid A, can we predict what the elastic properties are if the reservoir is saturated with fluid B? After Johnston 2013.

Generally, for depletion mechanisms that result in fluid-saturation changes:

- When water replaces oil or gas, the P-wave velocity, and density increase.

- For gas replacing oil or water, density, and P-wave velocity decrease.

- S-wave velocity remains relatively constant irrespective of the fluid replaces one another

For pressure or stress changes:

- When there is depletion of pressure or compaction of the reservoir will result in the increase P- and S-wave velocities as well as density.

- During injection, which will result in pressure increase, P- and S-wave velocities decrease. 
- In response to compaction in the reservoir, $\mathrm{P}$ - and $\mathrm{S}$-wave velocities change in the overburden and under burden. In the case of thermal recovery:

- As temperature increases, P-wave velocity decreases

- Whereas S-wave velocity decreases with increasing temperature if the oil is initially in a glass

or quasi-solid state.

It should be noted that just like the case of depletion mechanism, it is possible that more than one rock physics process can act in a reservoir. For instance, the 4D seismic changes for a producing reservoir where the pressure is below bubble point pressure will be a mixture of

(1) The decrease in velocity because of evolved gas from solution

(2) Increase in velocity because of increasing effective pressure of the rock.

In addition, seismic changes in thermal recovery should not always be ascribed to changes in temperature, in several instances especially with cyclic stimulation, time-lapse responses also come from steam.

\section{D SCREENING AND FEASIBILITY STUDIES}

Lumley et al., (1997) are one of the first people to discuss 4D screening in the literature, he created a "4D-technicalrisk spreadsheet" that allows a numerical score to a subset of the most important reservoir and seismic parameters that impact the technical chance of success of 4D. The choice of parameters includes reservoir, rock, and fluid properties and several seismic parameters as shown in (Table 1). There are differences between asset screening and full feasibility analyses and that difference is timing, the level of effort, and the questions to be answered. For asset screening, key average reservoir and seismic properties that affect the technical chance of success of a 4D project are usually evaluated. Asset screening usually involves a relatively low effort and is done early in a field's life to identify which fields warrant further analysis. Whereas Feasibility studies are used to study and determine the interpretability and magnitude of 4D seismic response, likewise feasibility studies help to plan the optimal time the monitor survey should be acquired, and also to know whether the previous seismic data can serve as a suitable baseline, and establish the cost/benefit value of the 4D project. Feasibility studies, unlike asset screening, involve a relatively higher effort and typically they are done after the completion of the initial field-depletion plan, geologic model during field-development planning after completion of the initial field-depletion plan, geologic model, reservoir-flow simulation, and facilities design. Tionet(2004) worked on a 4D feasibility study in order to determine if the dynamic changes occurring in a reservoir will be detectable on seismic data, and the result made him confident that future 3D seismic data will provide significant information about the reservoir dynamic characteristics. MacBeth et al. (2006) presented a method that can be used to calibrate individual 4D seismic attributes of any form with respect to the saturation and pressure changes in the reservoir, and this method is applied to a field over which two or more repeat surveys have been acquired at different times.

Screening studies evaluate the technical chance of a time-lapse seismic success by relying on average reservoir properties, meanwhile, feasibility studies rely on the full range of variation in rock properties, fluid saturation, and pressure to assess the 4D seismic signal. This can be done in one dimension by using well log data or in 2 or 3 dimensions by using reservoir simulation and geologic models, a process that is called simulation-toseismic (sim-to-seis) modeling.

This simulation-to-seismic process is not only a modeling approach that is important for the evaluation of a feasibility study but they are also essential for 4D seismic interpretation. 
Table 2: Reservoir, fluid, and seismic properties used for 4D screening. After Lumley et al., (1997).

\begin{tabular}{|c|c|}
\hline Reservoir component & Properties used to screen $4 \mathrm{D}$ \\
\hline Physical state & $\begin{array}{l}\text { Depth } \\
\text { Thickness } \\
\text { Water depth } \\
\text { Overburden pressure } P_{\mathrm{c}} \\
\text { Fluid pressure } P_{\mathrm{f}} \\
\text { Differential (effective) pressure } P_{\mathrm{d}} \\
\text { Temperature }\end{array}$ \\
\hline Rock & $\begin{array}{l}\text { Lithology } \\
\text { Dry-frame bulk modulus } K_{\text {dry }} \\
\text { Dry-frame density } \rho_{\text {ary }} \\
\text { Porosity } \phi\end{array}$ \\
\hline Oil & $\begin{array}{l}\text { API gravity } \\
\text { Solution GOR } \\
\text { Bubble-point pressure } \\
\text { Density } \rho_{\mathrm{o}} \\
\text { Bulk modulus } K_{\mathrm{o}}\end{array}$ \\
\hline Gas & $\begin{array}{l}\text { Specific gravity } \\
\text { Density } \rho_{g} \\
\text { Bulk modulus } K_{\mathbf{g}}\end{array}$ \\
\hline Water & $\begin{array}{l}\text { Salinity } \\
\text { Density } \rho_{w} \\
\text { Bulk modulus } K_{w}\end{array}$ \\
\hline Time-lapse changes & $\begin{array}{l}\text { Fluid-sa turation changes } \Delta S_{a}, \Delta S_{V} \Delta S_{w} \\
\text { Fluid bulk-modulus contrast } \Delta K_{f} \\
\text { Fluid pressure change } \Delta P_{f}\end{array}$ \\
\hline Seismic & $\begin{array}{l}\text { Dominant frequency } \\
\text { Average resolution } \\
\text { Image quality } \\
\text { Repeatability } \\
\text { Fluid-contact visibility } \\
\text { Predicted traveltime change } \\
\text { Predicted impedance change }\end{array}$ \\
\hline
\end{tabular}

\section{DATA INTEGRATION IN 4D SEISMIC APPLICATION}

Interpretation is where the rubber hits the road - the endpoint towards which all of the acquisition, processing, rock-physics analysis, reservoir engineering, and seismic modeling lead. Interpretation is where 4D seismic technology adds value to reservoir management. Just like there is no single way to interpret 3D seismic data, the same say there is no way to interpret 4D seismic data. In addition, any interpretation must be tied to a ground truth. For 3D data, we normally tie seismic to well log synthetics. Whereas for 4D data, we tie our interpretations not only to the well logs but also to dynamic reservoir parameters, such as a change in pressure, the rates of injection and production, cumulative production and injection, flow simulation, and repeat logs (e.g., PLTs).

The main objectives of a 4D reservoir-management project helps to determine the interpretation plan and process. For example the main objectives of 4D reservoir management can be met by a simple interpretation of sweep. Whereas, for other 4D projects, the quantitative estimates of pressure and saturation change might be required. Therefore, the fundamentals of an interpretation process can include:

1. Qualitative 4D interpretation: 4D signal can be because of changes in both saturation and pressure in the reservoir. Qualitative interpretations because of changes in saturation normally estimate the 4D seismic data in terms of sweep, to find flood fronts, bypassed oil, baffles, and movement of fluid contact. Interpreted pressure changes can be used to deduce compartmentalization, fault seal and connectivity. Occasionally pressure changes and saturation changes occur in the same place. In such instances, qualitative interpretation methods are not done in isolation, it is usually tied to production data and sometimes to 4D seismic modeling to resolve the uncertainties that arise from conflicting effects of pressure and saturation. The tie to production and simulation data typically is visual. That approach satisfies many reservoir-management needs. Uses of Qualitative interpretations include: to improve infill-well locations and well completion, to review reserves estimations and then to better manage water or gas sweep.

2. Reservoir-model updating: One of the important of Qualitative interpretation of the 4D seismic signal is that it serves as a template that can be used for manually updating the geologic and flow-simulation models. Such templates are useful as a guide for reservoir placement and to regulate flow parameters such as fault transmissibility or permeability multipliers. 4D response is eventually compared visually with the result of the model updates, and many examples of model updates use this approach.

3. Model-based interpretation. Simulation-to-seismic modeling is used to confirm and optimize geologic models 
and simulation models, by generating a synthetic 4D seismic response that can be compared either qualitatively or quantitatively with the actual 4D response. The outcomes are used to update the geologic model or simulation parameters iteratively to match both the seismic and production data. Manual update is the Common practice, Though, computer-assisted updates are becoming more common.

4. Quantitative 4D interpretation: In quantitative interpretation, saturation and pressure changes are estimated from the inversion of 4D seismic data that can be compared directly with reservoir-simulation predictions. This 4D interpretation process, which is currently an active research area, can offer extra reservoir insights, assist to resolve uncertainties in saturation and pressure responses, and also to evaluate uncertainty for 4D seismic predictions. It is important to note that quantitative interpretation can also help to make simpler computer aided-simulation history-matched algorithms.

The advance from qualitative to quantitative interpretation methods is essential to establishing the lasting worth of time-lapse seismic data. Each seismic survey denotes a photograph of the state of the reservoir at the time of data acquisition. Production continues, and the state of the reservoir changes after the data are recorded. Hence, 4D data grow stale as time passes, and their value reduces. Whereas reservoir models that are matched to 4D seismic data are more predictive, thus extending the worth of the seismic data by adding value through improved reservoir-management decisions.

\section{INTERPRETATION OF 4D AMPLITUDE DIFFERENCES}

Assuming that the baseline and monitor data have been properly processed by cross-equalizing and removing thee time shifts from the seismic difference. If the observed 4D seismic amplitude difference is a quadrature-phase peak or a zero-phase peak-trough, the reservoir will be interpreted to have an increase in impedance. The increase in impedance can be as a result of various process such as:

- Water replacing hydrocarbons because of waterflood or injection

- Oil replacing gas

- When reservoir pressure reduces but not below bubble point

- Reduction in pore spaces because of compaction

But if the observed 4D amplitude difference is a quadrature phase

trough or a zero-phase trough-peak as the case may be, a decrease in impedance will be interpreted within such a reservoir. Several processes can result in a decrease in impedance and they include:

- Gas replacing oil through gas-cap expansion, secondary gas-cap formation, or injection of gas

- Gas replacing water

- Oil replacing water

- Gas evolving from oil or water as pressure reduces below the bubble point

- an increase in reservoir pressure, generally as a result of injection

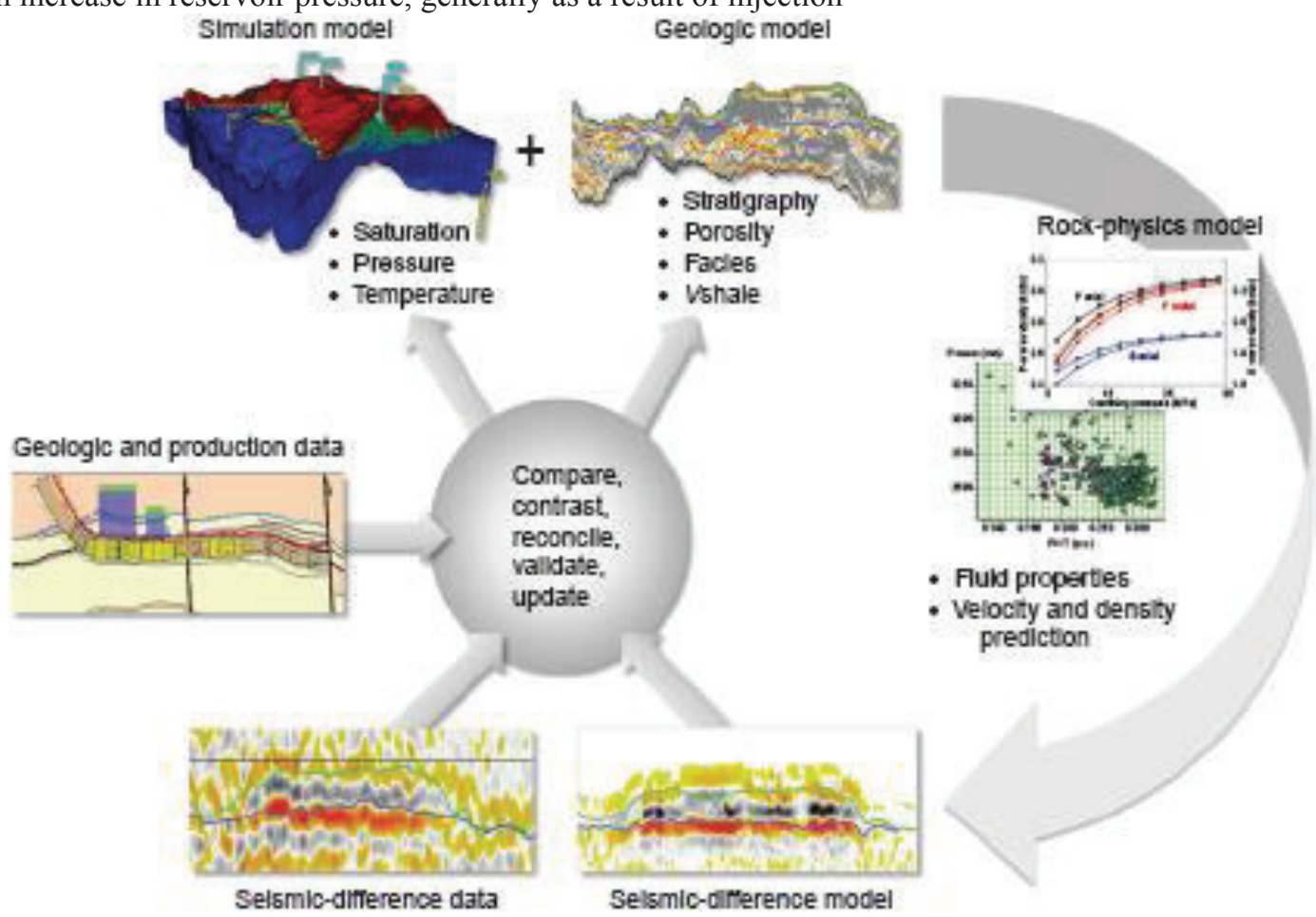

Figure 4: A workflow of model based 4D seismic interpretation after Johnston 2013. 


\section{D INVERSION}

Most times 4D amplitude interpretation is done on differences between two full-stack seismic data since such data compared to partial stacks have greater signal-to-noise values. Nevertheless, even when the 4D seismic response is dominated by changes in fluid-saturation changes resulting in changes in P-wave impedance alone, in such scenario full-stack data is not a true representative of a "zero-offset" seismic response. Hence, quadrature-phase data or inverted full-stack difference data can only be considered as a qualitative indicator of the actual impedance change. There is extra information present in partial-angle stacks, which encourages us to look for methods of elastic inversion of time-lapse data compared with the full stacks. 4D seismic inversion has several uses, which include:

-it can be used to estimate more robust estimates of $\mathrm{P}$-wave impedance, as a result reducing the sidelobe energy that can obscure the interpretation of quadrature-phase seismic data.

- $4 \mathrm{D}$ seismic inversion can also be used to estimates of S-wave impedance change, which can be beneficial in interpreting pressure changes

- It can also be useful in the estimation of quantitative impedance change that can be calibrated to rock-physics models

- It can also be useful in the better estimation of VP/VS values which can assist constrain reservoir presence because of the data redundancy essential in inverting multiple seismic surveys.

Sarkar et al. (2003) evaluated numerous time-lapse inversion workflows that can be employed to evaluate production-caused changes in subsurface properties. These include

- Individual inversion of baseline and monitor seismic data to impedance models, that is then differenced to obtain impedance changes

- The inversion of baseline data to acquire a baseline impedance model, which is afterward in the inversion as the initial model of the monitor data; the impedance models are then differenced to get a time-lapse impedance model (see also Lafet et al. 2005)

- Inversion of seismic differences (see also Buland and El Ouair 2006)

Inversion is intrinsically not unique. The results of Sarkar et al.'s (2003) model-based study suggest that inversion of time-lapse seismic data to time-lapse impedance changes needs coupling between the inversions of different data vintages. Not doing this coupling can cause artifacts in the resulting models, and that might lead to wrong time-lapse interpretations. Using a real deep-water clastic reservoir, three inversion workflows are tested using a 3D geologic model and a reservoir-simulation model. Using a simulation-to-seismic workflow, Sarkar et al. (2003) created synthetic 3D seismic volumes for preproduction baseline conditions and another for the pressures and saturations six years after production. The synthetic seismic volumes were later inverted for impedance change. A sparse-spike inversion algorithm is common to all three workflows.
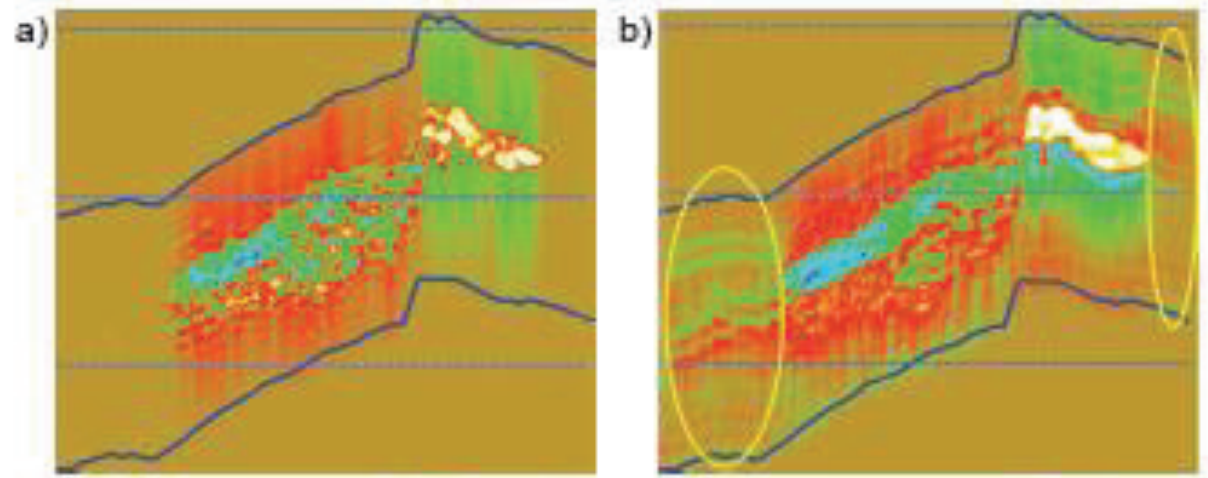

c)

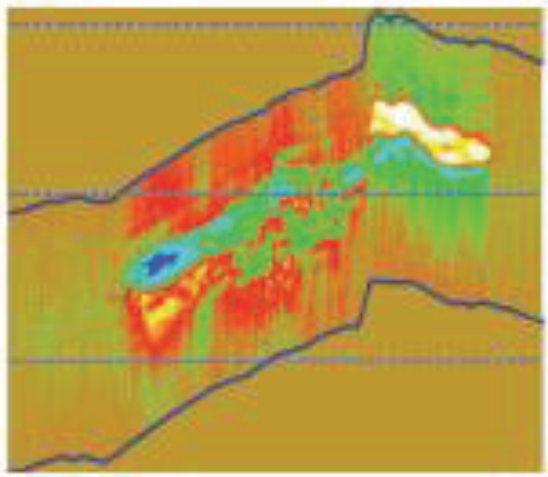

d)

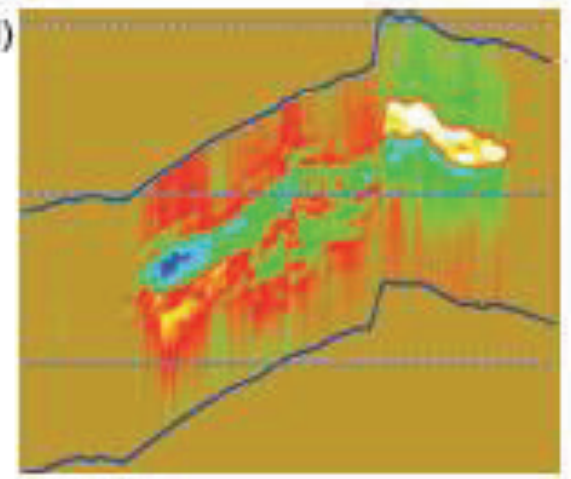

Figure 5. Impedance changes for different 4D inversion workflows. (a) The true impedance 
change obtained from a sim-to-seis workflow, (b) the results from an independent inversion of baseline and monitor synthetic-seismic volumes, (c) the results from a coupled inversion of baseline and monitor data, and (d) the results from an inversion of the difference. The circled areas in part (b) shows artifacts introduced into the result because of the nonunique nature of seismic inversion.

Such artifacts are significantly reduced if the inversions are coupled. After Sarkar et al.

(2003).

\section{CASE STUDIES}

The use of time-lapse seismic on reservoir management is completely understood especially in the deep-water settings of Nigeria because the current 4D seismic reservoir-monitoring projects have been fully utilized. The practical success of 4D seismic monitoring, its impact on reservoir management decisions, increased oil production and overall economic advantages of time-lapse seismic are illustrated in the following case studies.

\subsection{Gullfaks field, Norwegian North Sea}

The Gullfaks field is a field operated by Statoil, located roughly 50 miles east of the North Shetland Platform in the Norwegian section of the North Sea. The reservoir sands are of Jurassic age and they are deposits of shallow marine to fluvial. Brent Group abhors about $80 \%$ of the reserves in this field and the remaining in the statfjord, Lunde, and Cook formations. Exploration studies were carried out using the first seismic survey that was acquired in 1979, while the second seismic survey was acquired in the year 1985 after production started in the field.

Full production didn't start in the field till the year 1986 from the marine offshore fluvial reservoir sands which are of Jurassic age.

A time-lapse seismic study was conducted on the Tarbert formation in the year 1995 which is the upper-most producing unit in the field (Soenneland et al., 1997). The Tarbet formation is a member of the Brent Group with an average thickness of $180 \mathrm{ft}$ and an average porosity of 0.34 . The formation is characterized by clean, fluvial deltaic sandstone, while the pressure of the reservoir is being sustained by an active aquifer. (Veire et al, 1998). Gullfaks is a structurally complex field, with an eroded horst complex with sub-horizontal layers and steep faults, and a graben system as shown in figure 7 (Landro et al, 1999). The acoustic reservoir signature of the seismic survey in 1995 was compared with the baseline survey acquired in 1985.

The comparison and difference between the acoustic reservoir signatures assisted the company to determine the saturation changes and this also helps to locate bypassed pay. The replacement of oil by water in the Tarbert reservoir gives rise to a detectable 9\% change in seismic response, Fanchi, Pagano and Davis, 1999) while the presence or absence of gas is often more observable (Wang, 1997 and Fanchi, 1999). Bearing in mind that the Gullfaks field is dominated by fault-blocks, to improve field development it is needed to understand fault control on oil migration and reservoir compartmentalization. With the help of a 4D seismic data set, an innovative approach for fault-seal analysis was tried, and this has led to a better understanding of reservoir compartmentalization and also reservoir development. The reservoir-monitoring project at Gullfaks resulted in identifying two fault-block compartments that have initial oil saturation, and then a long horizontal well was drilled and completed through the compartments and a third region with a little diminished oil saturation. This new well established the distribution of oil saturation that was forecast by the time-lapse seismic project. Another well which was initially abandoned was sidetracked and re-completed in zones where the time-lapse study predicted that there was no drainage of oil, and the well produced a whooping 6000 barrel of oil per day. 


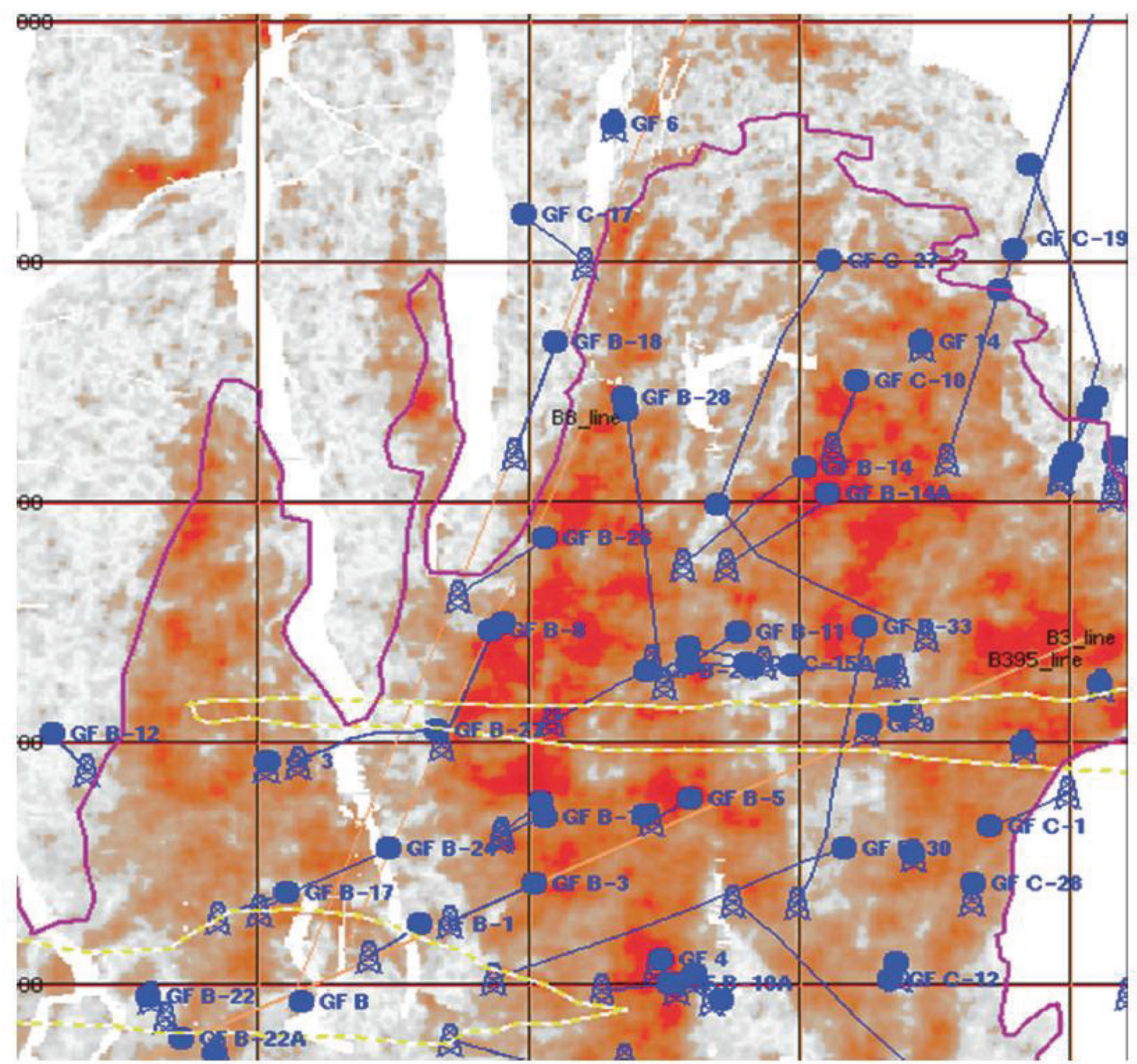

Figure 6 Amplitude map for the top reservoir event at Gullfaks. The purple solid line represents the original oilwater contact. Notice the strong correlation between high amplitudes (red colours) and presence of oil. The size of one square is 1,250 by $1,250 \mathrm{~m}$ Pressure

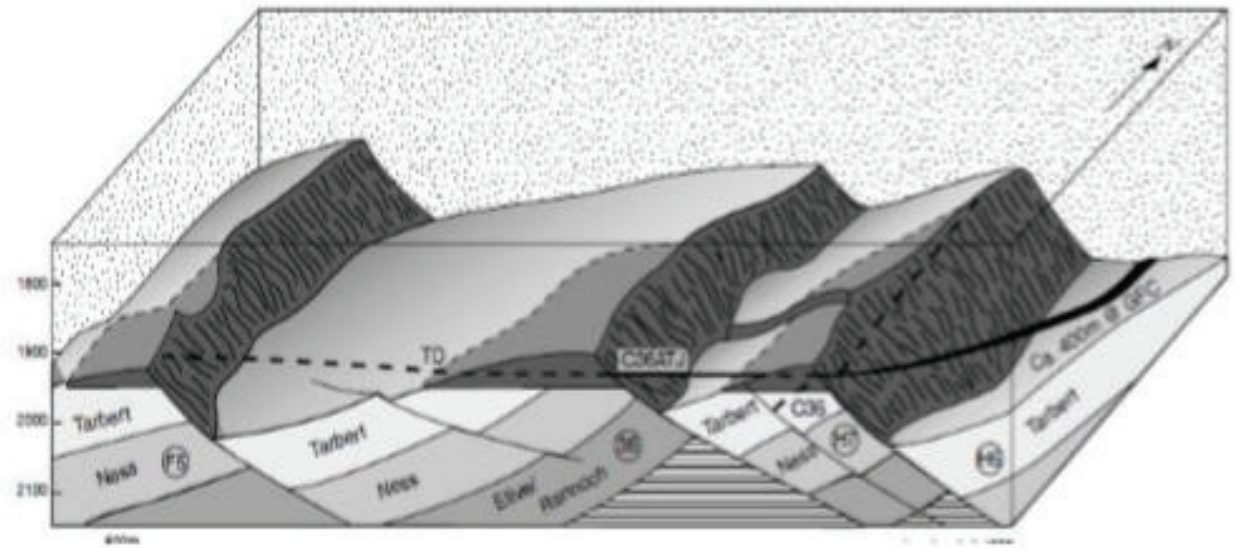

Figure 7. Gullfaks Field Geological Structure (After Landro et al 1999).

\subsection{Duri field, Indonesia}

Duri is a Chevron operated field, which consists of a shallow sand of early Miocene age with an average reservoir 
interval thickness of $107 \mathrm{~m}$. The reservoir is made up of three formations, which are: the Kedua, Lower Pertama and Upper Pertama formations, with an approximate porosity of $34 \%$ and $1.5 \mathrm{D}$ permeability. It is necessary to use steam flooding in this field because of the presence of heavy oil, which makes the primary recovery to be very low. The steam flood is used to mobilize the oil by heating it up and therefore decreasing its viscosity. The method of Steam flooding has succeeded in increasing the recovery factor from $8 \%$ to an economic level of $60 \%$ recovery (Jenkins, Waite and Bee, 1997). Duri has a heterogeneous reservoir, so it is often hard to tell where the steam flows to; the steam might be left in the ground, or probably directed incompetently along high permeability zones, thereby causing considerable parts of the reservoir undrained.

The objectives of the time-lapse seismic survey in the Duri field was to track the movement of the steam flood either horizontally and vertically across the field so that the injection can be well managed. Between 1992 and 1995, two baseline and six monitor 3D seismic surveys were acquired over the same steam injection pattern. Dynamite source and hydrophones for the receivers producing $100 \mathrm{~Hz}$ seismic were used for the seismic acquisition process.

The remarkable changes in the seismic surveys were associated with the conductive heating and effects of pressure. These changes were mostly enormous and were detected in a matter of a few months as shown in figure 2 (Jenkins et al, 1997). As a result of a combination of changes in the reservoir properties, a large time structure was developed inside and beneath the injection interval. This time structure increases in consecutive surveys and attained a maximum after 31 months. Some of the usefulness of the time-lapse survey includes stopping injection in the drained zones, flooding steam into cold zones and detecting observation wells. After the company went through the practical benefits of the survey, it was established that 4D seismic meaningfully improve injector profile management.
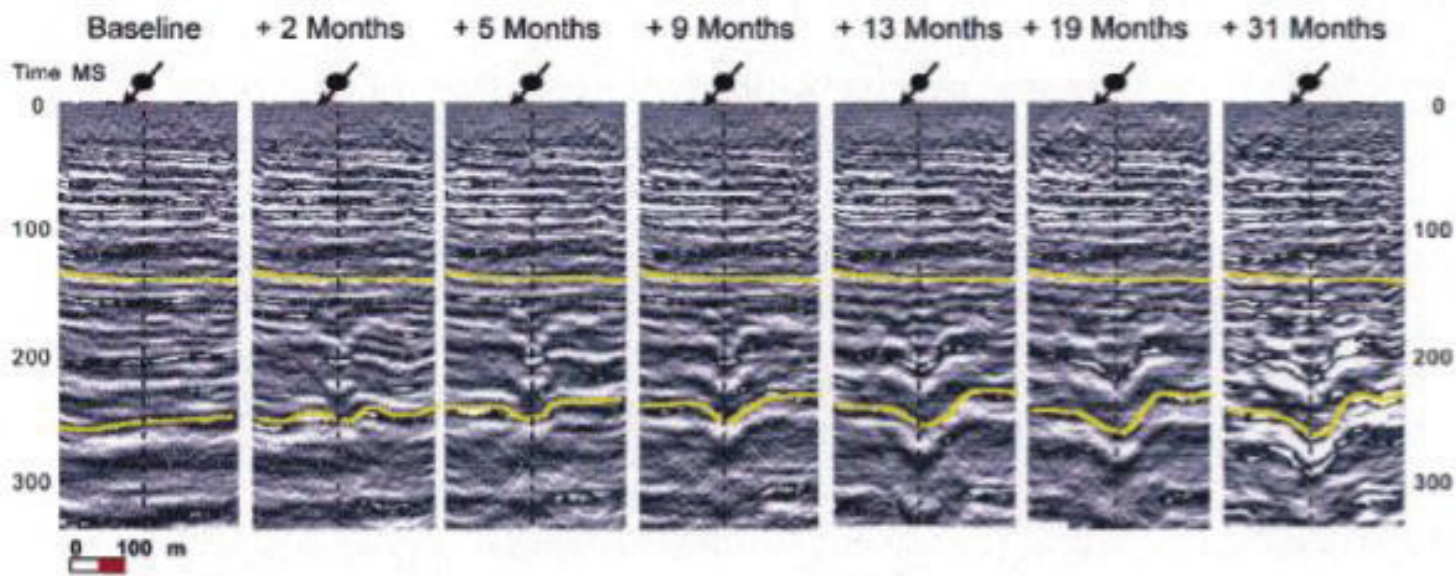

Fig. 8: A vertical section from baseline to six monitor seismic surveys. A synclinal shape due to gas in the reservoir is formed. (Reproduced from Jenkins et al., 1997)

\subsection{Eugene Island 330/338, Gulf of Mexico USA}

Eugene Island 338 and Eugene Island 330 are operated by Texaco and PennzEnergy respectively in the Gulf of Mexico, and these two fields are located next to each other at about 50 miles south of Louisiana coast. The 'LF' reservoir sand has a mean porosity of $27 \%$, an estimated permeability of $500 \mathrm{MD}$, and water saturation of $35 \%$. From 1974-1988 the Cumulative production from the reservoir was estimated to be 1.2 million bbl oil.

A 3-dimensional seismic data set of the reservoir was acquired in 1988, it was normalized and correlated to an earlier data set acquired in 1985. The company was able to identify areas where gas-oil ratios have increased in the 'LF' reservoir as a product of the presence of gas which is caused by the reduction in pressure which results in changes in the acoustic impedance of the reservoir. Similarly, recognition of the up-dip movement of the reservoir water-oil contact was possible because of the change in seismic response along the reservoir boundary.

The company was able to find bypassed oil and gas by detecting areas in the 3D data set that remained constant between 1985 and 1988, and as a result to a completion of a 1,200 ft horizontal well in the detected zone and primary production from this well exceeded 1,500 b/d in 1994 and by 1996 an increase of 1 million bbl have been added to the cumulative oil production of the field. A similar method was used on the 'IC' sand reservoir of Eugene 330 to discover bypassed oil, and in 1991 a well was successfully completed to increase the oil production by producing the by-passed oil. Other 3D seismic data sets were collected at Eugene Island 330/338 in 1992 and 1994. Each seismic is being combined with the two earlier data sets and presently serves as the foundation for multiple, current time-lapse studies. One important information that Eugene Island 330/338 confirmed is that a 3D seismic survey acquired before production started is useless (Fanchi et al, 1999). 


\subsection{Bonga field, Nigeria}

Bonga field in Nigeria is operated by Shell, it is located about $1 \mathrm{~km}$ in deep water, and it is approximately $120 \mathrm{~km}$ south-west of the Niger Delta Nigeria. The primary 3D seismic data in the field was acquired in the year 2000, and this was used as a guide for the positioning and drilling of wells and it also influenced other significant decisions before the beginning of production in November 2005. In 2008, a monitor survey was acquired and this took a period of 76, the acquisition was done utilizing 10 -streamer marine seismic acquisition vessel, source vessel and two support vessels (Detomo, 2008). Bonga field happened to be the first marine 4D seismic survey done in deep water in Nigeria. The whole process was technically complex and required several high-risk activities some of which include using air guns and towing long streamers at a near distance to the Bonga production fixed installations.

The purpose of the 4D seismic survey in this field was to better understand the reservoir drainage performance after two years of production and this will help guide the better placements of future wells in the field and in the end, the life cycle of the field will be optimized. The company made sure the design of this 4D acquisition was fully compatible with the first 3D survey acquired in 2000 and also future monitor 4D surveys projected to be acquired over the Bonga area. The Primary interpretation of the 4D data influenced operational performance and well planning which help to reduced uncertainty in the decisions that will give profit to all stakeholders.

Seismic interpretation in the field revealed two reservoir depositional types described as amalgamated lobes and channelized systems. The amalgamated lobe reservoir top and base can be picked on the zero crossings of the $90^{\circ}$ phase-rotated quadrature data (Figure 9a). The channelized systems are typically more complex because channel erosive edges, overlapping levees, aggradation, or laterally offset stacking geometries are present in the seismic (Figure 9b) Oghogho et al., 2015. These geometries are sometimes covered in shale drapes, causing waterflood behavior to be less predictable in the channelized systems. Multiple channel sets may either communicate during production or not, depending on whether the channel boundaries provide sand-on-sand juxtaposition or are draped with shale facies. Unfortunately, these microfacies are below seismic resolution. In the field study area, lithologies smaller than $2 \mathrm{~m}$ are not resolvable on seismic data.

Developed 4D seismic products from this survey continue to deliver new and beneficial results. Another significant part of this survey was the participation of Nigerians who made up about $40 \%$ of the employees on board. The seismic processing and interpretation of the seismic data were completed within the country thus providing Nigerian contractors and local Shell staff the chance to gain valuable deepwater 4D seismic experience.

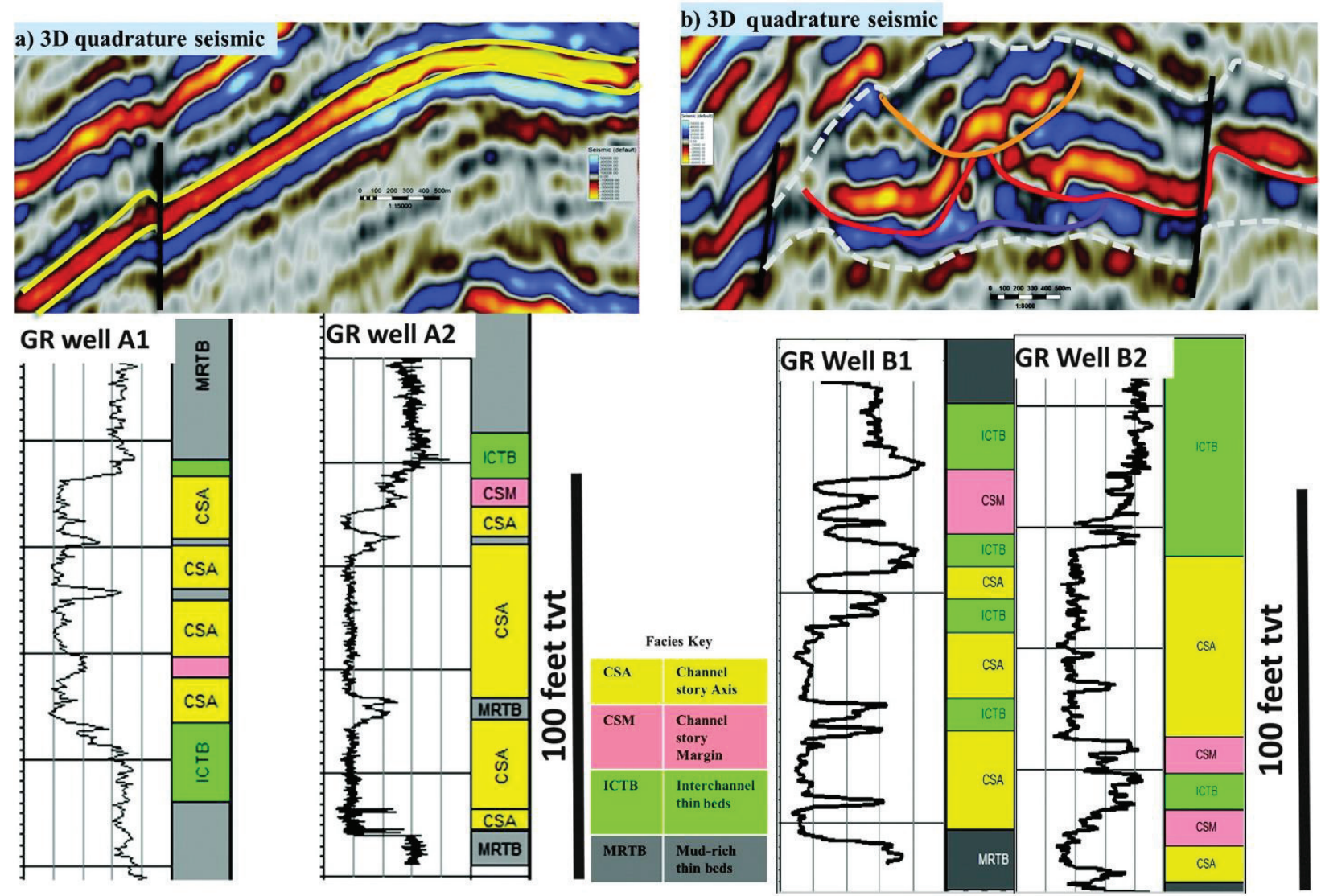

Figure 9. Panels ( $\mathrm{a}$ and $\mathrm{b}$ ) above are seismic cross sections across the depositional dip of two representative wells in the field. Reservoir A is geologically younger and made up of "layer-cake" sandy facies as seen in the gamma 
ray logs in well A1 and A2; whereas reservoir B is a deeper canyon system that has been infilled with other sandy channels with muddy intrachannel facies and thin beds identified by the gamma ray logs in Well B1 and B2. Oghogho et al., 2015

\subsection{Meren field, Nigeria}

Meren field is located in about 50feet deep of water (shallow water) and is south-east of Lagos Nigeria at about 10 miles offshore. Meren field is operated by Chevron and it has six fault blocks with over 40 producing reservoir sands. The total calculated original oil in place (OOIP) is 1.8 billion barrels of which 750 million barrels had been produced. The field produces a total of 85,000 barrels of oil per day, across reservoirs that are part of a set of sand -shale retrograde/ prograde near-shore depositional sequences. The oil in Meren field has a solution GOR of 400scf/STB, and this gives a good compressibility contrast with reservoir brine. The field was discovered in 1965 and first production began in 1968; with over 80 producer and injector wells. The baseline seismic survey was shot in 1987 while the 4D survey was acquired in 1996. A comprehensive 4D seismic interpretation of the Meren E-50 reservoir sand in Block 2, based on the extraction of horizon amplitude from the seismic survey of 1987 and 1996 cross-equalized seismic cubes were similar with well production histories at 22 of the 24 wells.

The 4D seismic interpretation suggested that water from two injectors has a preferential channel -flow characteristics, which point to a strong stratigraphic flow - unit overprint on the reservoir which was not previously evident from well data alone (Lumley, Nunns, Delorme, Adeogba and Bee, 2000). Likewise, three areas within the E-05 were identified to have contained major bypassed oil reserves and the 4D interpretation also gave a better description of the leaking or sealing nature of the reservoir faults was obtained.

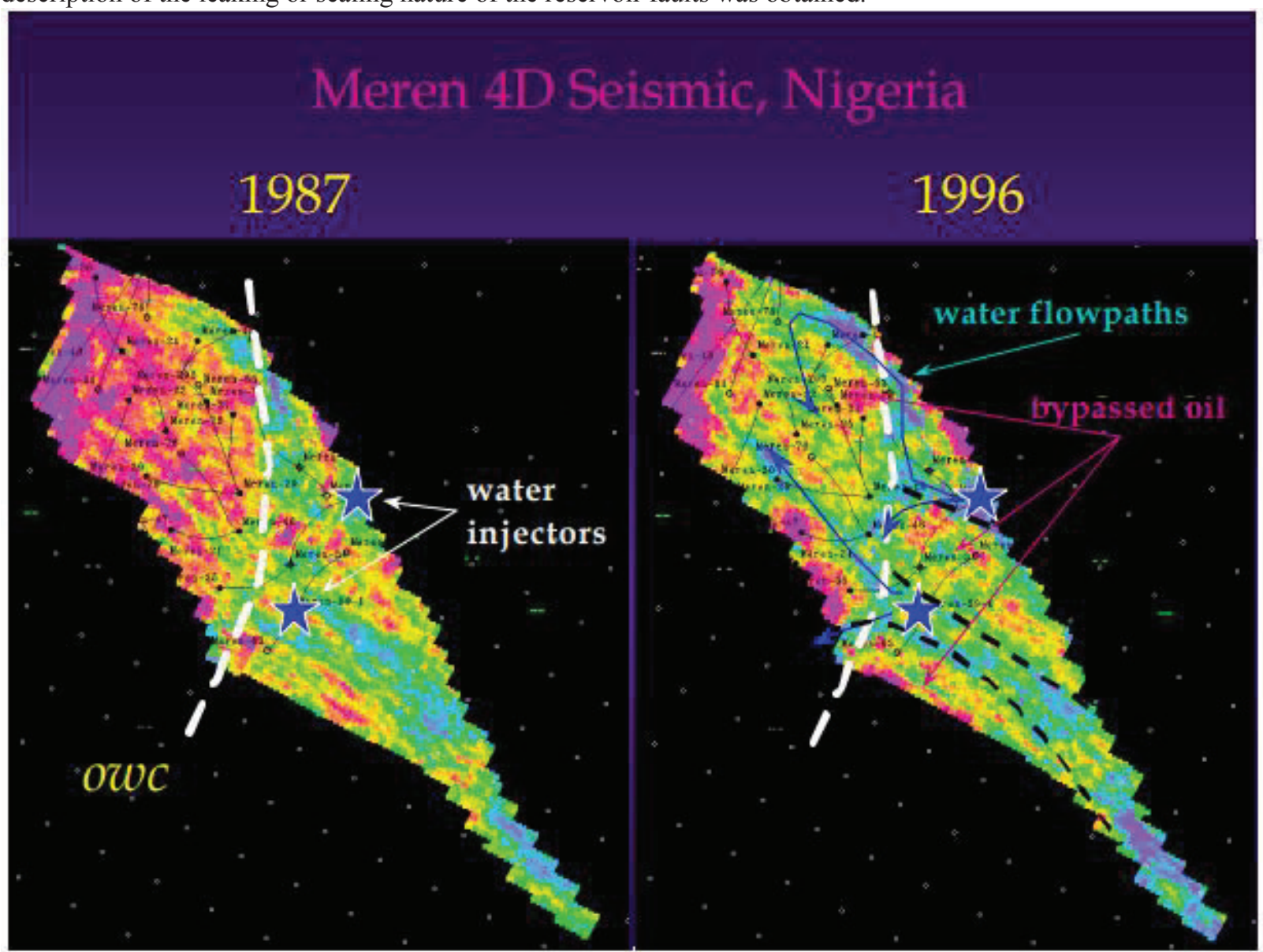

Fig. 10 - Meren E-05 reservoir, extracted horizon amplitude maps from 1987 survey (left) and 1996 survey (right). Red/pink amplitudes are consistent with high oil and gas saturations, blue/green amplitudes are consistent with high water saturation. The blue stars show the positions of the two water injectors. The oil-water contact from well data (dashed white line) correlates with the 1987 seismic, but not the 1996 data. The 4D seismic data suggest three areas of bypassed oil, isolated from the injectors by sealing faults (dashed black lines). Additionally, the 4D seismic shows highly channeled water flow along possible stratigraphic channels and across a leaking fault into an adjacent production block. Lumley et al., 2000 


\section{CONCLUSION}

A time-lapse seismic survey adds a cost of about $\$ 1 /$ barrel of oil produced while its benefit far outweighs this cost. Key benefits of 4D seismic include optimizing injector profile management, optimizing well placement, defining barriers to flow or compartments, assessing zones of undrained and bypassed oil, all of which lead to cost-effective increase in oil and gas production. Bonga field in Nigeria is a classical example of the success in the application of 4D seismic and most of the case studies are offshore. From the success, onshore fields are encouraged to benefit from this application of technology. Onshore oil fields in Nigeria should also have 4D seismic and more publications from companies operating in Nigeria are encouraged.

\section{REFERENCES}

Buland, A. and El Ouair, Y., 2006. Bayesian time-lapse inversion, Geophysics, Vol. 71, 3, R43-R48.

Calvert, R. 2005. Insights and methods for 4D reservoir monitoring and characterization, EAGE/SEG Distinguished Instructor Short Course 8

Detomo, R., 2008. Acquisition, Processing And Initial Impact Of The Bonga 4d Seismic Survey .Exploration And Production - Oil And Gas Review -Volume 8,Issue I

Fanchi, J.R., 1999. Flow models time 4D seismic surveys, OGJ, March 15th, 1999, pp46-51.

Fanchi, J.R., Pagano, T.A., and Davis, T.L., 1999. State Of The Art Of 4d Seismic Monitoring: The Technique, The Record And The Future, OGJ, May 5th, 1999.

Jenkins, S.D., Waite, M.W., and Bee, M.F., 1997. Time Lapse Monitoring Of The Duri Steam Flood: A Pilot And Case Study, The Leading Edge, September 1997.

Gassmann, F. 1951. Uber die Elastisitat Poroser Medien. Vierteljahrschr. Naturforsch. Ges. Zurich, 96, $1-23$

Goto R., Lowden, D., Smith, P., Paulsen, J.O., Osdal, B. and Aronsen, H. 2004. Steered-streamer 4D case study over the Norne field. SEG technical expanded abstracts, pp.2227-2230.

Jenkins, S.D., Waite, M.W. and Bee, M.,F. 1997. Time lapse monitoring of Duri steamflood: A pilot case study. The Leading Edge,16,1267-1273.

Johnston D H 2013. Practical Applications of Time-lapse Seismic Data. Society of Exploration Geophysicists. https:// doi.org/10.1190/1.9781560803126

Kragh, E. and Christie, P. 2002 Seismic repeatability, normalized rms, and predictability: The Leading Edge, 21, 640-647.

Lafet, Y., Duboz, P., Deschizeaux, B., Lefeuvre, F., and Hubans, C. 2005. 4D Stratigraphic inversion of the Girassol field - Towards a more quantitative approach, 67th EAGE Conference and Technical Exhibition, Madrid, Expanded Abstract C018.

Landrø, M., Solheim, O.A., Hilde, E., Ekren, B.O. and Strønen, L.K. 1999. The Gullfaks 4D Seismic Study. Petroleum Geoscience, v. 5, pp. 213-226.

Landrø, M. 1999a. Discrimination between pressure and fluid saturation changes from time lapse seismic data. 69th Ann. Internat. Mtg., Soc. Expl. Geophys., Expanded Abstracts, pp. 1651-1654.

Landrø, M. 1999b. Repeatability issues of 3-D VSP data. Geophysics, v. 64, pp.1673-1679.

Lumley, D. E., Behrens, R. A., and Wang, Z. 1997. Assessing the technical risk of a 4-D seismic project. The Leading Edge, v. 16, pp.1287-1291.

Lumley, D.E; Nunns,A.G; Delorme ,G; Adeogba,A.A; and Bee, M.F ; 2000. Meren field , Nigeria: A 4d Seismic Case Study .Offshore Technology Conference, May 2000, Houston Texas

MacBeth, C., M. Floricich, and J. Soldo. 2005. Going quantitative with 4D seismic analysis: Geophysical Prospecting, 54, 303- 317.

Mohsen Dadashpour . 2019. Reservoir Characterization Using Production Data and Time-Lapse Seismic Data Thesis presented for the degree of philosophy doctor at Norwegian University of Science and Technology Faculty of Engineering Science and Technology.

Oghogho Effiom, Robert Maskall, Edwin Quadt, Kazeem A. Lawal, Raphael Afolabi, Jake Emakpor, Reginald Mbah 2005. 4D seismic interpretation in a Nigerian deepwater field. Interpretation; 3 (2): SP11-SP19. doi: https://doi.org/10.1190/INT-2014-0198.1

Sarkar, S., Gouveia, W.P. and Johnston, D.H. 2003. On the inversion of time-lapse data, SEG Expanded Abstract, $1489-1492$.

Toinet, S. 2004. 4D Feasibility and Calibration Using 3D Seismic Modeling of Reservoir Models. Presented at Abu Dhabi International Conference and Exhibition, Abu Dhabi, 10-13 October. SPE-88783MS. https://doi.org/10.2118/88783-MS.

Wang, Z.J., 1997. Feasibility of Time Lapse Seismic Reservoir Monitoring: The Physical Basis. The Leading Edge, September 1997, pp.1327-1329.

Wang Z. 2001. Fundamentals of seismic rock physics Geophysics 66 398-412 